ISROMAC-11 Proceedings of the International Symposium on

Transport Phenomena and Dynamics of Rotating Machinery, Feb.26-March 2, 2006, Honolulu, Hawaii, USA

\title{
Aerodynamic Drag Characteristics and Shape Design of a Radar Antenna Used for Airport Ground Traffic Control
}

\author{
Baris Gumusel ${ }^{1}$, Levent Kavurmacioglu ${ }^{2}$ and Cengiz Camci ${ }^{3}$ \\ Turbomachinery Aero-Heat Transfer Laboratory \\ The Pennsylvania State University \\ 223 Hammond Building, University Park, PA 16802 \\ 8148659871 fax : 8148657092
}

ABSTRACT

Modern air traffic control systems in airports use high-speed ground tracking radars usually rotating at 60 $\mathrm{rpm}$. The flow induced vibration and noise generation of the newly developed radar antennas are the two serious problems that jeopardize the successful deployment of the new ground aircraft tracking systems. The present study is an attempt to understand the viscous flow characteristics around a typical radar antenna cross section via computations. After a steady-state validation of the computations, a parametric study of possible new shape designs for the antenna is discussed. The present computations are validated by using a well-known experimental data set for a cylinder in cross flow, at the operational Reynolds number of 426,000 . The predicted drag coefficient for the cylinder agrees well with the measured $C_{D}$ values. Significant aerodynamic drag reductions via careful shape design of the antenna are possible. Elongating the original antenna cross section in the chordwise direction by keeping the antenna height constant is an effective aerodynamic solution for further drag reductions.

1 Graduate Research Assistant

2 Visiting Professor

3 Professor of Aerospace Engineering, ( $\underline{\operatorname{cxc} 11 @ \text { psu.edu }})$
INTRODUCTION

More recent " Airport Surface Detection Equipment" (ASDE-X) using radar technology requires that the antennas rotate at a minimum speed of $60 \mathrm{rpm}$.

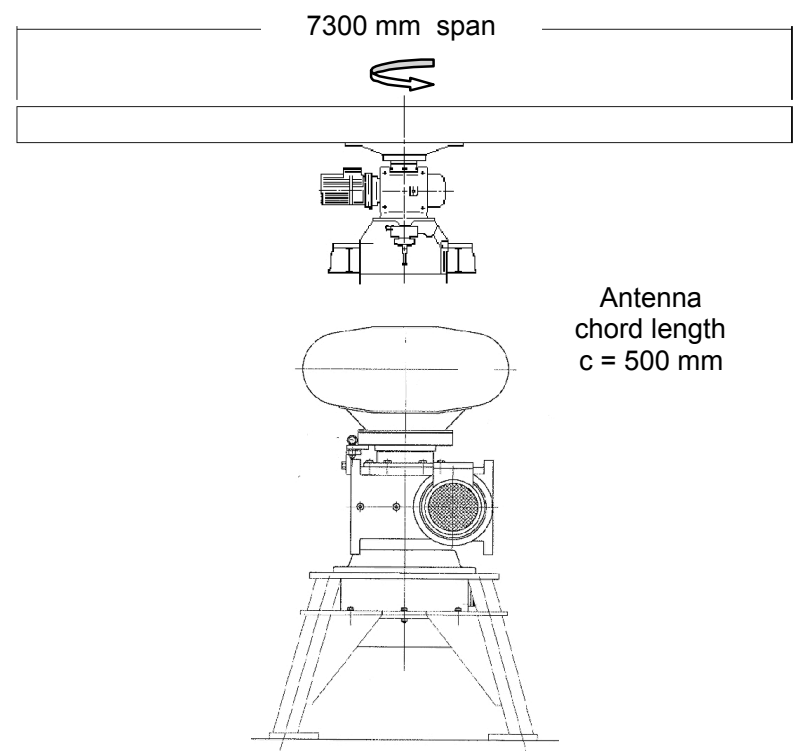

Figure 1. The rotating antenna ASDE-X head used for airport ground traffic control

This recently imposed rotational speed comes from the fact that the ground traffic in a modern airport is tracked and updated once every minute 
The current paper summarizes the findings of a Computational Fluid Dynamics (CFD) study performed for the improvement of ASDE-X antenna operation. The vibration and noise generation of the newly developed ASDE-X radar antenna as shown in Figure 1 is a serious problem that jeopardizes the successful deployment of this new airport ground traffic control system. The most significant problem areas are aerodynamically induced noise and vibration. The overall project has three main areas of investigation.

\footnotetext{
1. Experimental wind tunnel research of aero-acoustic/structural characteristics of a scaled rotating antenna model.

2. Analytical and numerical studies of aero acoustics.

3. Computational Fluid Dynamics studies of the current ASDE-X cross-section and other possible geometries.
}

A computational fluid dynamics approach for an accurate assessment of the aerodynamic drag coefficient is used. Proper grid clustering near the wall in the viscous sub-layer and the use of a parallel computer cluster comprised of 24 processors are essential in obtaining accurate aerodynamic results in a time efficient manner. The fluid dynamics details of the re-circulatory flow zones and wakes are simulated at high resolution. The current computational methodology is validated using well-established wind tunnel data for cylinder-incross-flow from Prandtl and Tietjens [1] and Wieselsberger [2]. Additional experimental results are also presented in Flaschsbart [3,4] and Roshko [5]. Other "validation quality" wind tunnel studies on cylinder in cross flow are reported in references from [6] to [10]. After the establishment of the validity of cylinder-incross-flow computations against wind tunnel data, the actual ASDE-X antenna cross-section shown in Figure 2 is computationally evaluated. In addition, two elongated ellipses are compared against the actual ASDE-X antenna shape and the cylinder.

If one replaces the ASDE-X cross section with a cylinder (having the same antenna maximum thickness $\mathrm{H}=0.272 \mathrm{~m}$ ) the aerodynamic drag coefficient increases about $23 \%$ relative to the ASDE-X antenna. When the ASDE-X antenna is replaced with an "equivalent ellipse" having the same fineness ratio $\mathrm{FR}=\mathrm{c} / \mathrm{H}$, the aerodynamic drag coefficient is reduced about $35 \%$ relative to the original ASDE-X cross-section.

The drag coefficient of the ASDE-X cross section could be reduced to half of its original value by simply elongating the ellipse shape to a fineness ratio of $\mathrm{FR}=\mathrm{c} / \mathrm{H}=2.757$ from the original ASDE-X FR value of 1.838. The elongated ellipse for this case has the new chord length of 1.5 times the original ASDE-X chord.
Further elongation of the ellipse to fineness ratios of $\mathrm{FR}=3.5$ and 4.5 seems to provide significant relative improvements.

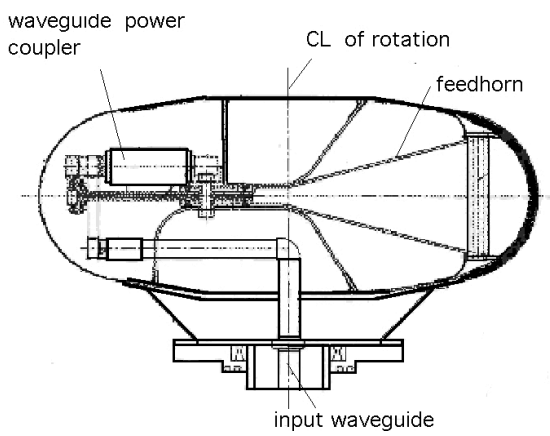

Figure 2. Structural details of the rotating antenna head and the overall aerodynamic shape

\section{GOVERNING EQUATIONS}

The numerical simulations of the steady-state 2D flow around the ASDE- $X$ antenna cross section are obtained by solving the incompressible Reynolds Averaged Navier-Stokes equations. The simulations were obtained using the computer code Fluent 6.0 on high quality viscous flow grids. The computational grid systems used are a mix of block-structured and unstructured grids. A two-equation turbulence model based on K-epsilon RNG Re-normalization Group model was used in all calculations, Yakhot and Orszag [11]. The near wall treatment was applied without using conventional wall functions. The momentum equations were integrated down to $\mathrm{y}^{+}=1$. This approach places a strong emphasis on the quality of the near wall grid system, because of the strong interest in the prediction the drag coefficient of the antenna cross-section. The continuity equation and momentum equations in this model are:

$U_{i, i}=0 \quad$,

and $\quad \rho U_{j} \frac{\partial U_{i}}{\partial x_{j}}=-\frac{\partial p}{\partial x_{i}}+\mu \frac{\partial^{2} U_{i}}{\partial x_{j} \partial x_{j}}+\frac{\partial R_{i j}}{\partial x_{j}}$

where $\quad R_{i j}=-\rho \overline{u_{i} u_{j}}$ are the Reynolds Stresses. The Reynolds stresses are modeled by using the Boussinesq hypothesis. 
$R_{i j}=-\rho \overline{u_{i} u_{j}}=-\rho \frac{2}{3} k \delta_{i j}+\mu_{t}\left(\frac{\partial U_{i}}{\partial x_{j}}+\frac{\partial U_{j}}{\partial x_{i}}\right)$

For two-equation models, the turbulent viscosity is related to turbulent kinetic energy $k=\overline{u_{i} u_{i}} / 2$ and the dissipation rate $\varepsilon$ as $\mu_{t}=\rho C_{\mu} k^{2} / \varepsilon$. The turbulent kinetic energy equation is as follows,

\section{BOUNDARY CONDITIONS}

Most of the initial calculations were performed for the full-scale ASDE-X tip cross section. A $60 \mathrm{rpm}$ antenna rotational speed was applied. The tip section of the antenna has a linear speed of $\mathrm{U}_{\text {tip }}=22.9 \mathrm{~m} / \mathrm{s}$ for the tip diameter of $\mathrm{D}=7.3 \mathrm{~m}$ at $\mathrm{N}=60 \mathrm{RPM}$. The computational domain is a large rectangular area where

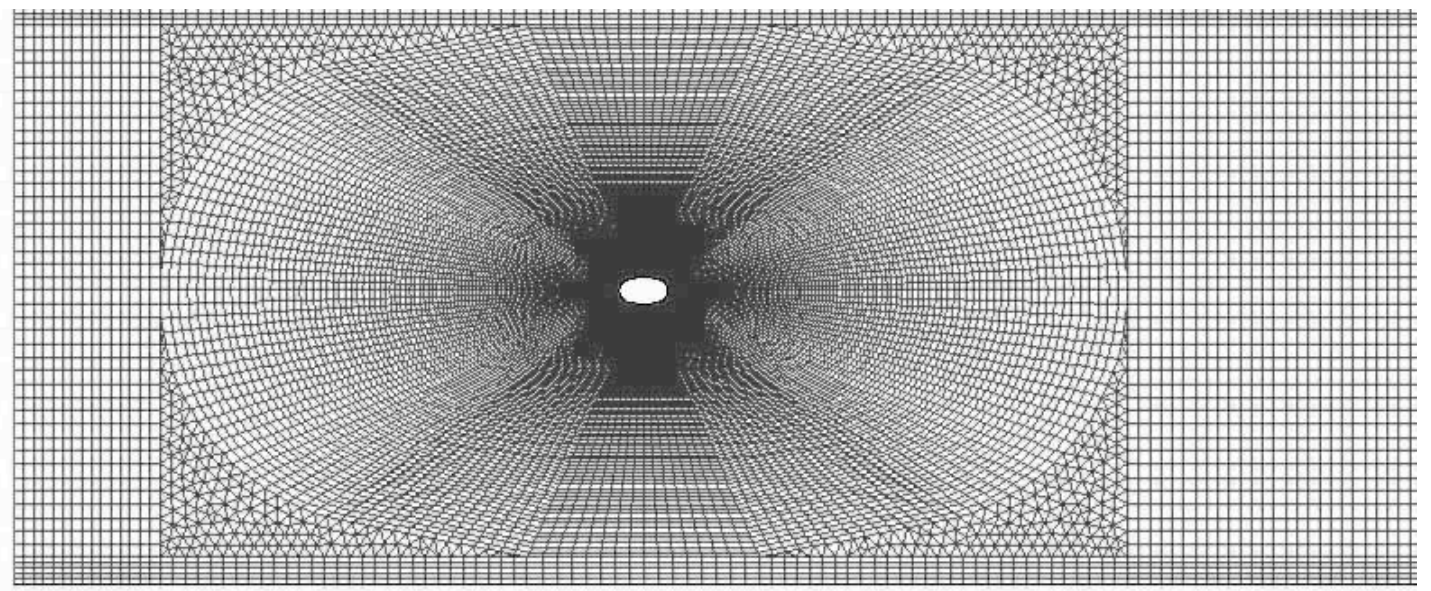

Figure 3 2D computational domain 41626 grid point (a mix of block structured and unstructured grid)

$\rho U_{i} \frac{\partial k}{\partial x_{i}}=\mu_{t}\left(\frac{\partial U_{j}}{\partial x_{i}}+\frac{\partial U_{i}}{\partial x_{j}}\right) \frac{\partial U_{j}}{\partial x_{i}}+\downarrow$

$\Rightarrow+\frac{\partial}{\partial x_{i}}\left\{\left(\mu+\mu_{t} / \sigma_{k}\right) \frac{\partial k}{\partial x_{i}}\right\}-\rho \varepsilon$

The dissipation rate equation is,

$$
\begin{aligned}
& \rho U_{i} \frac{\partial \varepsilon}{\partial x_{i}}=C_{1 \varepsilon} \frac{\varepsilon}{k} \mu_{t}\left(\frac{\partial U_{j}}{\partial x_{i}}+\frac{\partial U_{i}}{\partial x_{j}}\right) \frac{\partial U_{j}}{\partial x_{i}}-C_{2 \varepsilon} \frac{\varepsilon^{2}}{k}+\alpha \\
& \Rightarrow+\frac{\partial}{\partial x_{i}}\left\{\left(\mu+\mu_{t} / \sigma_{\varepsilon}\right) \frac{\partial \varepsilon}{\partial x_{i}}\right\}
\end{aligned}
$$

where

$$
\sigma_{k}=1, \quad \sigma_{\varepsilon}=1.3, \quad C_{1 \varepsilon}=1.44, \quad C_{2 \varepsilon}=1.92
$$

are empirical constants.
Ine $\angle \mathrm{V}$ antemina cross-section is tocated in tne cemtral section of the domain as shown in Figures 3 and 4. The left face of the domain was assigned a uniform velocity inlet boundary condition of $22.9 \mathrm{~m} / \mathrm{s}$. The top and bottom walls of the computational domain use a zero stress boundary condition in order to eliminate the development of boundary layers and an eventual core flow blockage. The antenna surface uses a no-slip boundary condition. The downstream boundary conditions impose that the streamwise gradients of the mean velocity components are zero at the exit section (outflow condition). A turbulence intensity of $\mathrm{Tu}_{\infty}=0.5 \%$ and a turbulent length scale of $\mathrm{L}=0.25 \mathrm{~m}$ are imposed at the inlet section. These are estimated average values of atmospheric turbulence that might occur around a typical ASDE-X antenna. The air density at standard sea level conditions was taken as $\rho=1.225 \mathrm{~kg} / \mathrm{m}^{3}$. The molecular viscosity used in the calculations is $\mu=1.789 \times 10^{-5}$. The Reynolds number of the tip section is $\mathrm{Re}=\left[\rho \mathrm{U}_{\text {tip }} \mathrm{H} / \mu\right]=$ 426,000 based on $\mathrm{U}_{\text {tip }}=22.9 \mathrm{~m} / \mathrm{s}$ and $\mathrm{H}=0.272 \mathrm{~m}$ $(\mathrm{H}=$ maximum height of the antenna cross section) at 60 RPM. The chord length of the actual ASDE-X cross section is $0.5 \mathrm{~m}$. 

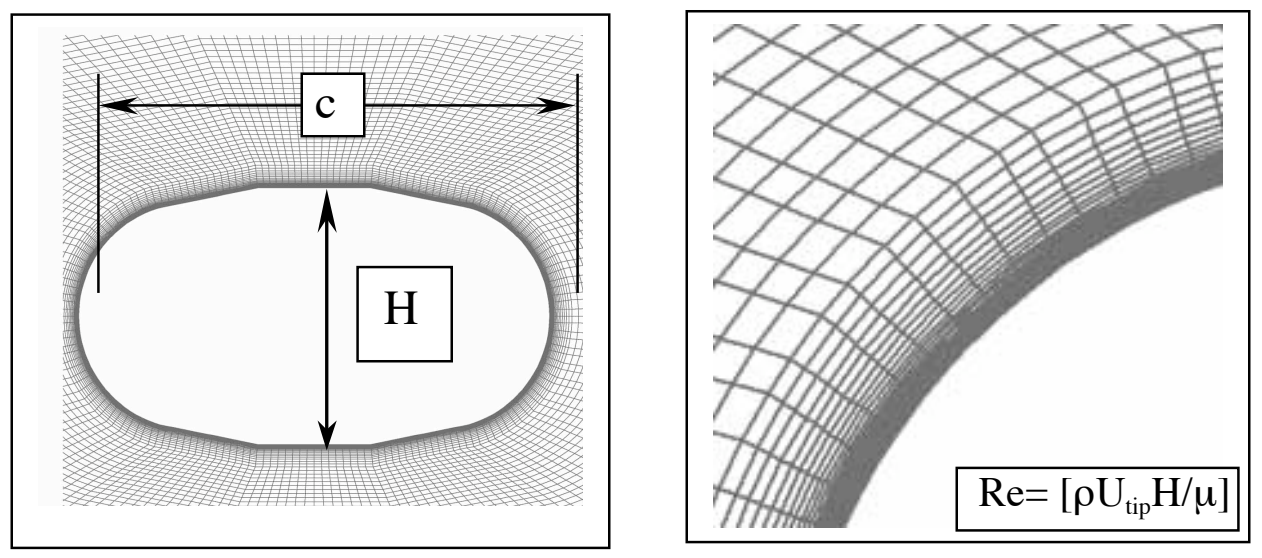

Figure 4. Grid system near the antenna and the boundary layer grid used in drag coefficient calculations

\section{$\mathbf{c} / \mathbf{H}=$ fineness ratio}

\section{VALIDATION OF THE COMPUTATIONS}

Validations For A Cylinder In Cross Flow: The accuracy of drag coefficient computations were checked by using a well established experimental data set from Wieselsberger [2] as published by L.Prandtl [1] and H.Schlichting [8]. Figure 5 shows the variation of drag

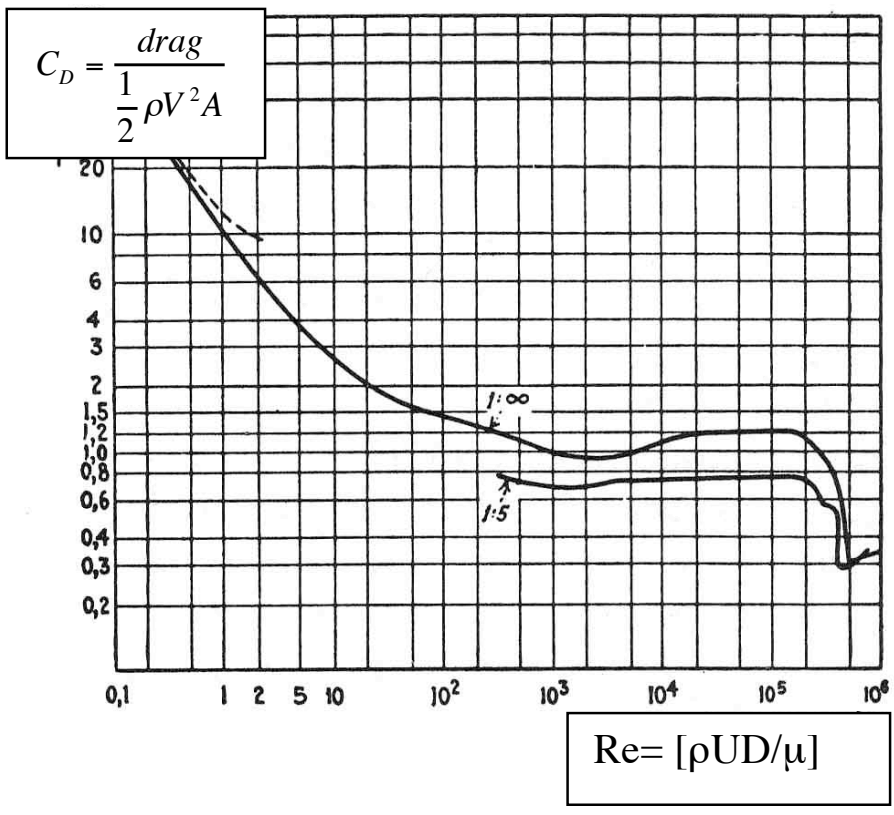

Figure 5. $C_{D}$ with respect to $\mathrm{Re}=\rho \mathrm{U}_{\text {tip }} \mathrm{H} / \mu$ for a circular cylinder of infinite aspect ratio and finite length to diameter ratio of $5: 1$, references [1],[2],[5] coefficient $C_{D}$ with respect to $R e=\rho U_{\text {tip }} H / \mu$ for a circular cylinder of infinite aspect ratio and finite length to diameter ratio of $5: 1$. The $C_{D}$ data set was obtained by systematically increasing cylinder diameters so that the Reynolds numbers above $10^{4}$ are covered.

The measured data set shows a transition to supercritical operation at $R e=400,000$. The values before $\mathrm{Re}=200,000$ are usually termed as "laminar" in the literature. Below $\operatorname{Re}=200,000$, the onset of separation point is on the frontal part of the cylinder near $90^{\circ}$ point.

The drag coefficient remains constant at a value around $C_{D}=1.2$ in a wide Reynolds number range from $R e=1000$ to 200,000. Increasing $\mathrm{Re}$ in this wide range does increase the drag force, however the increase in the denominator of the drag equation (Dynamic head $\mathrm{x}$ Frontal area) results in a constant drag coefficient. After $\mathrm{Re}=200,000$, the onset of separation point near the $90^{\circ}$ point moves to the aft part of the cylinder all of a sudden. Any small increase in this range results in further closing of the wake region around the cylinder. The overall wake dimension in cross-stream direction becomes smaller and smaller with increasing Reynolds number. The $\mathrm{C}_{\mathrm{D}}$ values continually decline up to $\mathrm{Re}=450,000$. The inset in the lower figure shows $C_{D}$ variation this special region. The drag coefficient slightly increases between $\mathrm{Re}=450,000$ and $1,000,000$. The pressure drag in this range is likely to increase faster.

The current validation of the computations was performed at the actual tip $\mathrm{Re}_{\text {tip }}=426,000$ of the ASDE$\mathrm{X}$ antenna. Drag coefficient of a circular cylinder at this specific Reynolds number was computationally investigated. The current computations predict a cylinder drag coefficient of $C_{D}=0.375$. This computationally predicted value is in very good agreement with the measured drag coefficients as shown in Figure 6. 


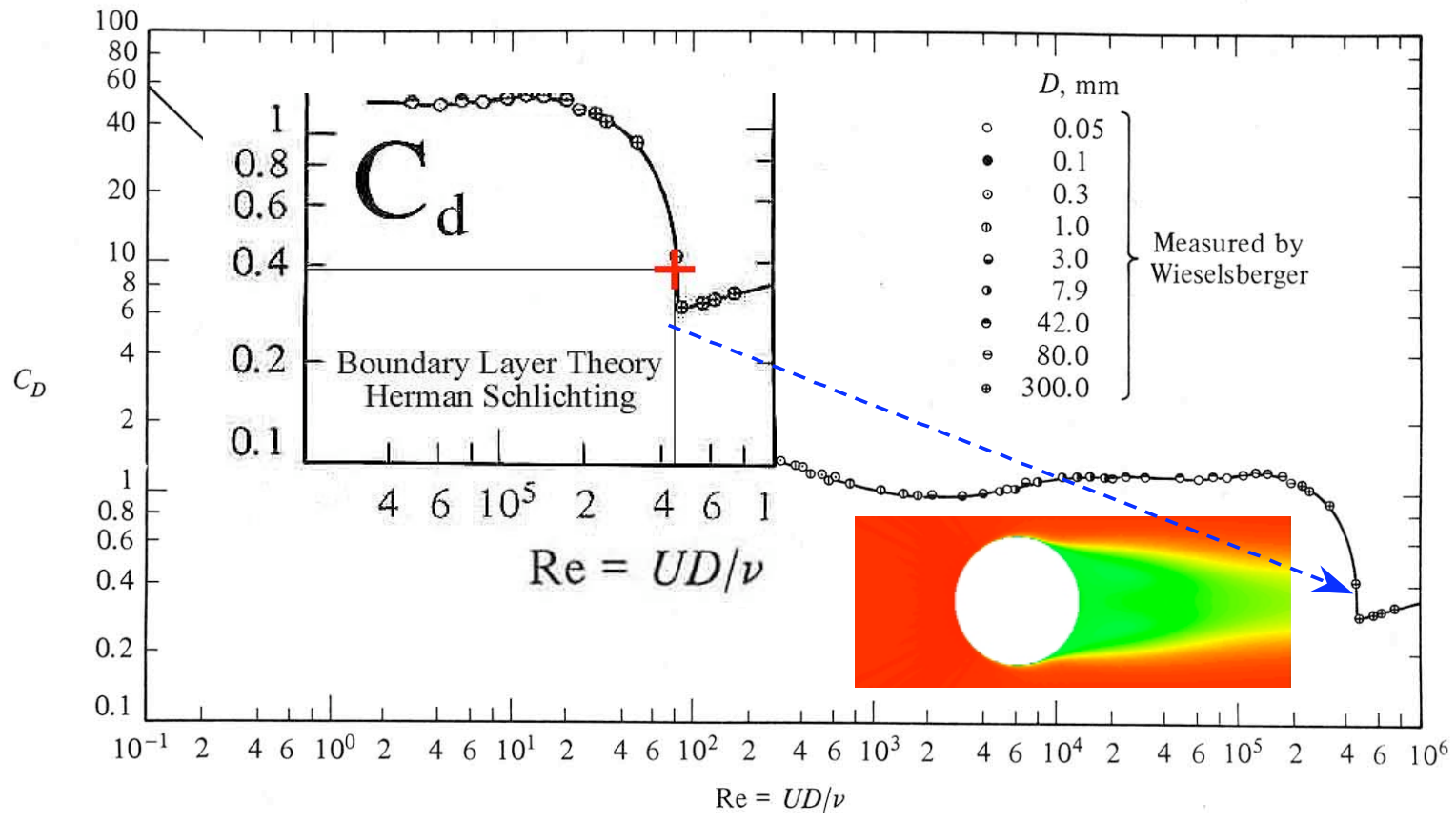

Figure 6. Wieselsberger's [2] cylinder in cross flow measurements from Prandtl and Tietjiens [1] The red plus symbol is the present computational prediction of $C_{D}=0.3754$ at $R e=426,000$

Figure 6 is usually used as a summary of Wieselsberger's experiments for $\operatorname{Re}>10,000$. Ellipse in cross flow experimental data is also provided for various fineness ratios $(\mathrm{FR}=\mathrm{c} / \mathrm{H})$ in Figure 7 . The term laminar is used for the $\mathrm{Re}$ range before the discontinuity around $\mathrm{Re}=200,000$, where the term "turbulent" is used for the range after $\mathrm{Re}=450,000$. The current computational predictions for the cylinder and ellipse are also in good agreement with the summary table given in [11]. A second validation computation for an ellipse of $\mathrm{FR}=1.83$ was performed. The predicted $C_{D}$ value for this ellipse was 0.196 . This value compares well with the measured $C_{D}$ value of $0.20(F R=2)$ from Figure 7.

\section{COMPUTATIONAL RESULTS AND DISCUSSION}

This section presents results for the drag coefficient of a reference cylinder having the same frontal area of the ASDE-X antenna, the actual antenna geometry and two other suggested cross sections for the future antenna designs. The drag coefficient in this investigation is defined as $C_{D}=d r a g /\left(0.5 \rho V^{2} A\right)$ where "drag" includes both pressure drag and viscous drag forces. $\mathrm{A}$ is the frontal area of the antenna cross section which is defined as $\mathrm{A}=[\mathrm{H} \times$ Antenna length $]$ where $\mathrm{H}$ is the maximum thickness of the ASDE-X cross-section or the diameter of the reference cylinder. Antenna length is unity for 2D calculations. The 2D solid contours shown in Figures 8, 10 and 11 show the distribution of total pressure as an indication of local momentum deficit in the boundary layer and wake. Red is the highest total pressure and green is the lowest level of total pressure.

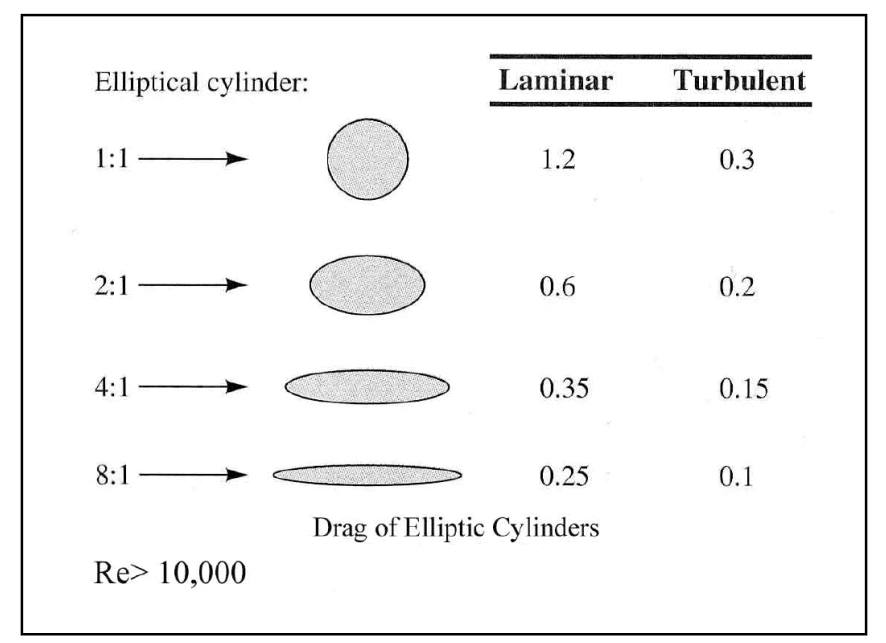

Figure 7. A summary of measured drag coefficients for $\operatorname{Re}>10,000$ for a circular cylinder and ellipses of various fineness ratios $(\mathrm{FR}=\mathrm{c} / \mathrm{H})$, White [11]. 


\section{DIFFERENT GEOMETRIES WITH THE SAME FRONTAL AREA}

Figure 8 compares the computed drag coefficients for the ASDE-X tip cross section, a reference cylinder, and two ellipses having the same effective cross section. The viscous force in horizontal direction, the pressure force and the total horizontal force is presented. The horizontal force components are calculated by integrating the wall shear stress and pressure over the aerodynamic shapes. The highest drag value is assigned to the cylindrical cross section due to a relatively early onset of separation point near the $90^{\circ}$ location. Moving from the cylinder to ASDE-X cross section, presents a $19 \%$ improvement in the drag coefficient. Figure 8 shows that an ellipse of the same fineness ratio as the ASDE-X antenna can improve the drag coefficient by about $\mathrm{RI}=35 \%$. When the ellipse is elongated further to $\mathrm{FR}=\mathrm{c} / \mathrm{H}=2.75$, a significant $\mathrm{C}_{\mathrm{D}}$ gain in the order of $\mathrm{RI}=50 \%$ is obtained when compared to the ASDE-X cross section. The "relative improvement RI" is defined as the ratio of "the drag coefficient reduction" divided by the "drag coefficient of ASDE-X cross section". In elliptical cross sections, the wake thickness and the momentum deficit is effectively reduced.

The influence of increasing the fineness ratio of an elliptical cross section at the tip Reynolds number level is presented in Figure 7. An ellipse of $F R=2.75$ results in a $C_{D}$ of 0.1511 . This relative improvement level is equivalent to about $\mathrm{RI}=50 \%$ of the ASDE-X cross section $C_{D}$ value. Increasing the fineness ratio from $\mathrm{FR}=2.75$ to 3.5 only results in a relative improvement in aerodynamic performance $(\mathrm{RI}=54 \%)$. The highest fineness ratio of $F R=4.5$ results a $C_{D}$ of 0.1317 with a relative improvement value of $\mathrm{RI}=56 \%$. Figure 8 clearly show that the most dramatic improvement in using elliptic antenna shapes can be obtained when the ASDE$\mathrm{X}$ cross section is replaced with an ellipse of equivalent $\mathrm{FR}=1.838$ and 2.757. Although further elongation of the antenna shape brings improved drag coefficients, the operation of the extremely flat elliptical shape with an increased chord length may prove difficult from fluidsolid interaction point of view. Figure 9 shows additional computational results from $\mathrm{FR}=3.5$ and 4.5 ellipses. Extremely flat elliptical shapes may also result in radar antenna integration problems in the rotating cross section.

\section{CROSS SECTIONS BETWEEN THE ANTENNA HUB AND TIP}

Figure 10 shows the computed drag coefficients for the ASDE-X cross-section at four different radial positions from the tip to hub (25\% radius). Since the antenna is rotating at $60 \mathrm{RPM}$, the linear velocity of the sections at $100 \%, 75 \%, 50 \%$ and $25 \%$ tip radius result in different Reynolds numbers. The four radial sections are indicated in the solid model of the antenna in Figure 10.

The drag coefficients slightly increase from 0.3032 to 0.3180 from tip to hub because of the decrease in Reynolds number assigned to each section at 60 RPM. The total increase is within $1.8 \%$ of the tip value of $C_{D}$. The total pressure values in each section and the horizontal total force (viscous + pressure) are reduced significantly from tip to hub. The $25 \%$ radius section near the hub experiences 15 times less total force when compared to the tip section, due to important reductions in the dynamic head assigned to this cross section. The ratio of the viscous force to pressure force in each section remains approximately constant at about $9 \%$.

\section{COMPARISON BETWEEN THE FULL SCALE AND SMALL SCALE COMPUTATIONS}

The aerodynamic performance of the scale wind tunnel antenna used in this study was compared to the full scale ASDE-X antenna cross section at the tip section. The only computational difference in the two case is in the Reynolds number assigned to each cross section. The actual antenna rotating at $60 \mathrm{rpm}$ had a tip speed of 22.9 meters corresponding to a tip Reynolds number of 426,000. 1/10 scale antenna used in the wind tunnel studies was rotated at 600 RPM so that the tip speed of the wind tunnel model matches the tip speed of the actual ASDE-X antenna. The computational results for the full scale operation is given in the top row of Figure 11. The wind tunnel model tip Reynolds number was 10 times smaller compared to the actual ASDE-X antenna. The lower row of Figure 11 is for the $1 / 10$ scaled model operating at $\mathrm{Re}=42,600,(\mathrm{H}=0.0272 \mathrm{~m}), 600 \mathrm{RPM}$.

The predicted drag coefficient for the 1/10 scale wind tunnel model is $C_{D}=0.3566$. The relative increase in the drag coefficient is about $17 \%$ with respect to full scale operation. Although the change in Reynolds number is 10 fold, a slight change in the computed drag coefficient was observed. This weak Reynolds number dependency of computations is consistent with measured trends. 


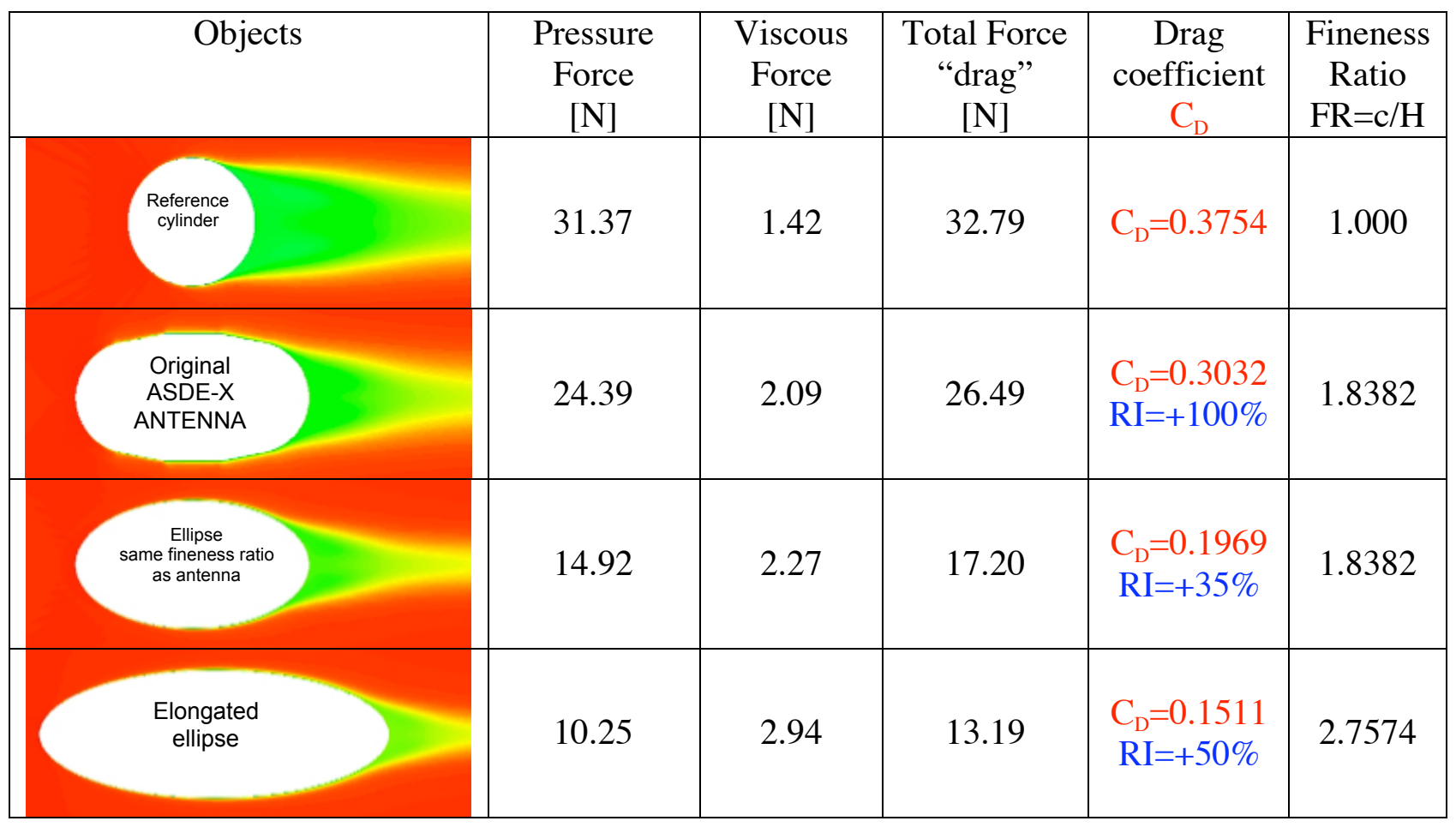

Figure 8. A comparison of the computed ASDE- $X$ antenna aerodynamics with a cylinder and two ellipses, $\mathrm{H}=0.272 \mathrm{~m}, \mathrm{c}=\mathrm{FR} \times \mathrm{H}, \mathrm{Re}=426,000$

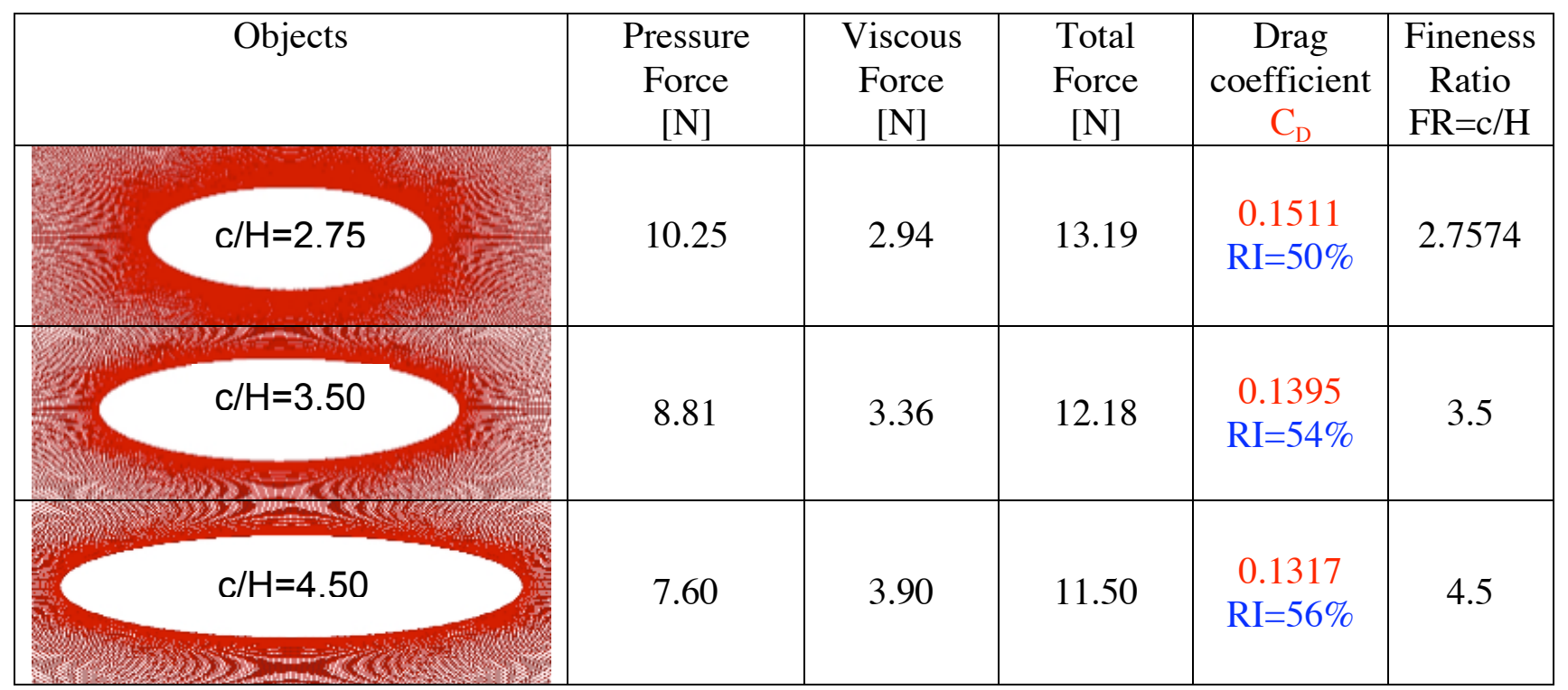

Figure 9. A comparison of three elliptical cross sections

with different fineness ratios $\mathrm{H}=0.272 \mathrm{~m}, \mathrm{c}=\mathrm{FR} \times \mathrm{H}, \mathrm{Re}=426,000$ 


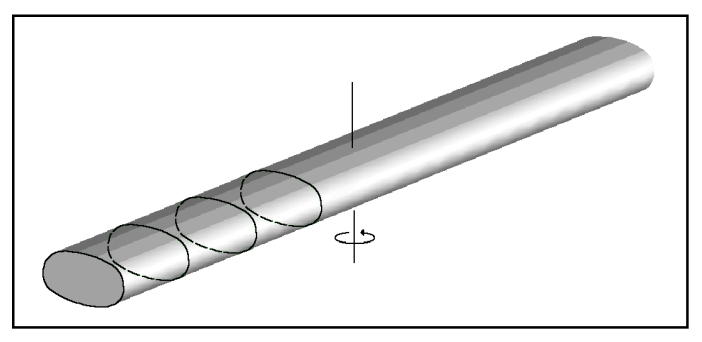

\begin{tabular}{|c|c|c|c|c|c|}
\hline Objects & $\begin{array}{c}\text { Pressure } \\
\text { Force } \\
{[\mathrm{N}]}\end{array}$ & $\begin{array}{c}\text { Viscous } \\
\text { Force } \\
{[\mathrm{N}]}\end{array}$ & $\begin{array}{c}\text { Total } \\
\text { Force } \\
{[\mathrm{N}]}\end{array}$ & $\begin{array}{c}\text { Drag } \\
\text { coefficient } \\
C_{D} \\
\end{array}$ & $\begin{array}{c}\text { Fineness } \\
\text { Ratio } \\
\mathrm{FR}=\mathrm{c} / \mathrm{H}\end{array}$ \\
\hline $\begin{array}{c}\text { TIP } \\
100 \% \\
\text { RADIUS }\end{array}$ & 24.39 & 2.09 & 26.49 & 0.3032 & 1.8382 \\
\hline $75 \%$ & 13.83 & 1.24 & 15.08 & 0.3061 & 1.8382 \\
\hline $50 \%$ & 6.22 & 0.60 & 6.82 & 0.3099 & 1.8382 \\
\hline $\begin{array}{c}\text { HUB } \\
25 \% \\
\text { RADIUS }\end{array}$ & 1.56 & 0.17 & 1.73 & 0.3180 & 1.8382 \\
\hline
\end{tabular}

Figure 10. Aerodynamic performance of the ASDE-X antenna at four radial positions from tip to hub

\begin{tabular}{|c|c|c|c|c|c|}
\hline Objects & $\begin{array}{c}\text { Pressure } \\
\text { Force } \\
{[\mathrm{N}]}\end{array}$ & $\begin{array}{c}\text { Viscous } \\
\text { Force } \\
{[\mathrm{N}]}\end{array}$ & $\begin{array}{c}\text { Total } \\
\text { Force } \\
{[\mathrm{N}]}\end{array}$ & $\begin{array}{c}\text { Drag } \\
\text { coefficient } \\
\mathrm{C}_{\mathrm{D}}\end{array}$ & $\begin{array}{c}\text { Fineness } \\
\text { Ratio } \\
\text { FR=c/H }\end{array}$ \\
\hline $\begin{array}{c}\text { FULL } \\
\text { SCALE }\end{array}$ & 24.39 & 2.09 & 26.49 & 0.3032 & 1.8382 \\
\hline $1 / 10$ SCALE & 2.78 & 0.33 & 3.11 & 0.3566 & 1.8382 \\
\hline
\end{tabular}

Figure 11. A comparison of the full scale ASDE- $\mathrm{X}$ antenna and the $1 / 10$ scale $P S U$ wind tunnel model, $\mathrm{c} / \mathrm{H}=1.8382$ 


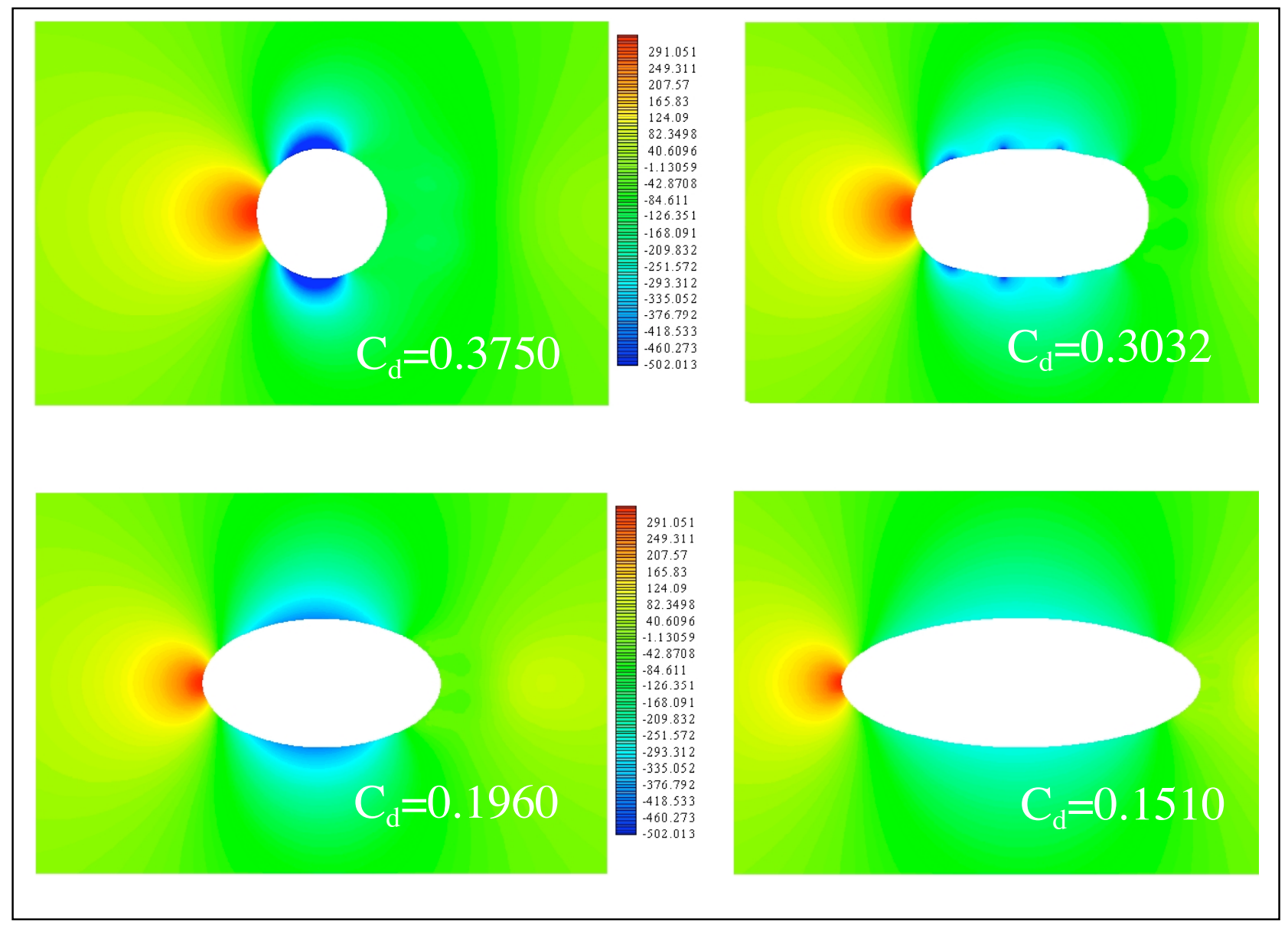

Figure 12. Static pressure field around the cylinder, antenna and two ellipse cross sections (in $\mathrm{N} / \mathrm{m}^{2}$ )
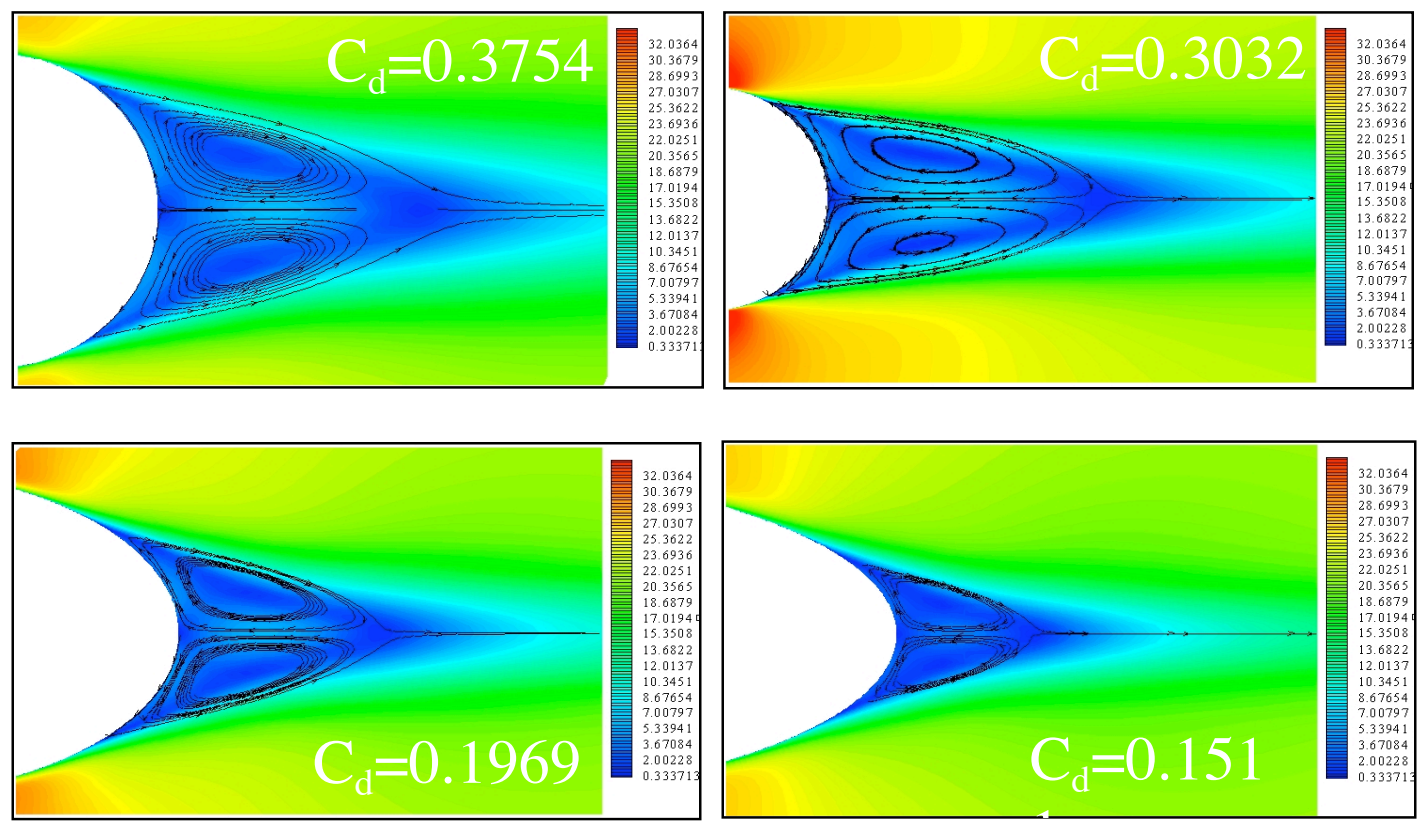

Figure 13. Wake re-circulatory flow structure around the cylinder, antenna and two ellipse cross sections Solid colors indicate magnitude of velocity (the same legend for Figures 6, 8, 10,11 and 13) 
Figure 12 shows the influence of aerodynamic shape design on the static pressure distribution around the reference cylinder, actual ASDE-X antenna and two elongated ellipses. The static pressure disturbances generated by the sharp corners of the original ASDE-X antenna are clearly visible in Figure 12. Figure 13 presents the numerical simulation of the streamlines in the re-circulatory flow zone of the four aerodynamic objects. A clear reduction in the size and momentum deficit of the wakes from ellipses is noticeable. A reduced wake size and momentum deficit is expected to reduce the severity of the wake-antenna interactions. The interactions may be strong especially when cross-winds are existing around the rotating antenna assembly. This is the case where the antenna may be chopping its own wakes due to highly three dimensional wind loads.

\section{CONCLUSIONS}

The results from a "computational fluid dynamics" study around an ASDE-X antenna are used to understand viscous flow details and vortex shedding characteristics under "full scale" and "scaled model" operating conditions.

The computational method using a two-equation (KEpsilon RNG) turbulence model with a near wall grid addressing the need for the discretization of the viscous-sub layer are the two key elements in predicting pressure drag and viscous drag.

The present computations were validated by using well known experimental data for a cylinder in cross flow case, at the full scale Reynolds number of 426,000. The predicted drag coefficient for the cylinder agrees very well with the measured $C_{D}$ values.

If one replaces the ASDE-X cross section with a cylinder (having the same antenna maximum thickness $\mathrm{H})$ the aerodynamic drag coefficient increases about $23 \%$ relative to the ASDE-X antenna. Although it may not be possible to house an antenna in a cylindrical geometry, this case was studied as a reference shape for which there is extensive experimental fluid mechanics data.

If the ASDE-X antenna is replaced with an "equivalent ellipse: having the same fineness ratio, the aerodynamic drag coefficient could be reduced by about $35 \%$ relative to the original ASDE-X cross section.

The drag coefficient of the ASDE-X cross section could further be reduced to half of its original value by simply elongating the ellipse shape to a fineness ratio of $\mathrm{FR}=\mathrm{c} / \mathrm{H}=2.757$ from the original ASDE-X FR value of 1.838. The elongated ellipse for this case has the new chord length of 1.5 times the original ASDE$\mathrm{X}$ chord.

Further elongation of the ellipse to fineness ratios of $\mathrm{FR}=3.5$ and 4.5 seems to provide relative improvements of $\mathrm{RI}=54 \%$ and $\mathrm{RI}=56 \%$, respectively. Although a relative improvement in $\mathrm{C}_{\mathrm{D}}$ is observed, due to increased antenna perimeter, these flattened shapes may be very sensitive to varying external aerodynamic conditions in terms of fluid-solid interaction characteristics.

The drag coefficients slightly increase from a tip value of $\mathrm{C}_{\mathrm{D}}=0.3032$ to 0.3180 at the $25 \%$ antenna radius (hub). Due to a monotonic reduction in linear speed at each radial position, the horizontal aerodynamic force (pressure+viscous force) is about 15 times smaller at the hub (25\% radius) than the tip value. This prediction suggests that fluid solid interactions near the tip section is much more significant in the last quarter of the antenna radius.

The aerodynamic performance of the scale wind tunnel antenna used in this study was compared to the full scale ASDE-X antenna cross section at the tip section. The predicted drag coefficient for the $1 / 10$ scale wind tunnel model is $C_{D}=0.3566$. The relative increase in the drag coefficient is about $17 \%$ with respect to full-scale operation. Although the change in Reynolds number is 10 fold, a slight change in the computed drag coefficient was observed. This weak Reynolds number dependency of computations is consistent with measured drag coefficients of aerodynamic objects such as cylinders and ellipses.

\section{ACKNOWLEDGMENTS}

Prof.D.K.McLaughlin of the Aerospace Engineering Department was instrumental in initiating this research effort. The authors are also indebted to Rick Auhl, Mark Catalano, Michael Caldwell and Kirk Hellen for their their technical support. The current study used Fluent 6 as a general-purpose computational fluid dynamics solver. 


\section{REFERENCES}

[1] Prandtl, L. and Tietjens, O.J., 1934, "Applied Hydro- and Aeromechanics," Dover Publications, Inc. ISBN 486-60375-X, New York.

[2] Wieselsberger, C., 1914, "The Air Resistance of Spheres (German)," Z.Flugtech. Motorluftschiffahrt, Vol.5, p.140.

[3] Flaschsbart, O., 1927, "New Experiments on the Air Resistance of Spheres," (German), Physik. Z., Vol.28, p.461.

[4] Flaschsbart, O., 1932, “ Winddruck auf Gasbehalter," Reports of the AVA in Gottingen, IV th Series, pp. 134-138.

[5] Roshko, A., 1970," Experiments on the Flow past a Circular Cylinder at very High Reynolds Numbers," Journal of Fluid Mechanics, Vol.10, pp. 345-356.

[6] Homann, F., 1936, "Einfluss Grosser Zahigkeit bei Stromung um Zylinder," Forsch.Ing-Wes.7, pp.110.

[7] Jones, G.W., Ginotta, J.J. and Walker, R.W., (1969), "Aerodynamic Forces on a Stationary and Oscillating Cylinder at high Reynolds Numbers," NACA TR-R-300.

[8] Schlichting, H., 1979, "Boundary Layer Theory," Seventh Ed. Mc-Graw Hill, New York.
[9] Blevins, R.D., 1984, “ Applied Fluid Dynamics Handbook," Van Nostrand Reinhold, New York.

[10] Hoerner, S.F., 1965 "Fluid Dynamic Drag," Library of Congress Number 64, 19666.

[11] V.Yakhot, and S.A. Orszag, 1986 " Renormalization Group Analysis of Turbulence", J. Sci. Comput. 1, 3 .

[12] White, F., 2002, "Fluid Mechanics," Fifth edition, McGraw-Hill, ISBN: 0072831804. 